\title{
Os Sublimes Duelos Amorosos
}

Flor Marlene E. Lopes

Apresento aqui algumas reflexões a respeito da comédia e da tragédia que sublimam o discurso amoroso. Parto, essencialmente, dos seguintes textos: Werther, de J. W. Goethe; das evocações de R. Bathes, em Fragmentos de um discurso amoroso e do curta-metragem, Carlota Amorosidade, de A. Ruiz.

A história de uma paixão é a impotência, a distância, o sofrimento, a impossibilidade de estar com o outro. Esta incomunicabilidade está sobredeterminada por uma forte e ineludível epistemização de saberes e de crenças: há por trás de tudo o imperativo de estar juntos.

Carlota Amorosidade é a história de uma paixão, e, portanto, é a história de um duelo obsessivo entre um estado efetivo em que se encontra o sujeito apaixonado e um estado simulado que esse sujeito, Werther, projeta para si. Aqui, o amor é pateticamente disfórico, de fato, nāo há nenhum idílio.

Esse conflito interno do sujeito, esse duelo entre duas realidades (essa crise) exprime-se por um /querer-ser/ que passa a significar, cntão: uma conjunção ao modo do parecer e uma disjunção ao modo do ser. Aqui, é claro, esse/querer-ser/ que modaliza o sujeito apaixonado vem a ocuparolugar de uma carência, uma falta, um vazio existencial que é um anti-objeto de valor com o qual o sujeito está em conjunção ao modo do ser. 
A relação não é nem sensual, nem de comunhão efetiva e intelectual. A separação das almas não é total por causa das particularidades desses dois mundos não "objetiváveis", fruto de uma construção imaginária do sujeito. As coisas se complicam ainda mais, quando vemos as projeções que cada um elabora de si. Os valores que o sujeito tem como desejáveis, irá projetá-los na figura do ser amado.

Nesse processo, nada envolve efetivamente a pessoa amada. No caso de Werther, por exemplo, o seu objeto, Cartola, não tem o mesmo projeto de vida que o apaixonado: ela é noiva (está em conjunção, ou, pelo menos, está em nãodisjunção) de Alberto, que figurativiza todos os valores que Werther quer abandonar (/querer-não-ser/).

Incomunicabilidade trágica difícil de transcender, que faz da dupla fantasmas sem nenhuma verdadeira e autêntica coesão. Há um jogo de imagens que funciona, portanto, como uma grade epistêmica interposta, como um sistema de interpretações e de crenças opacas que anulam toda possibilidade de comunicação.

Amar, no caso de Werther, significa estar em crise, padecer atrozmente, produzir um conflito, um desdobramento entre identidades contrárias. O ciúme nasce precisamente no momento em que este nāo pode considerar a mulher como seu objeto, ou a vítima de sua apropriação, mas deve constatar que ela se tomou o objeto de algum outro.

Semioticamente,estas identidades têm que ser entendidas como dois universos de valores, vale dizer, dois sujeitos delegados desses universos, postos em conflito. Dito de outro modo, é a produção de simulacros, ao modo do parecer:

- quando Werther ama Carlota, ele ama na verdade um simulacro: ele ama o Werther que ele deveria ser.

- quando Werther odeia Alberto, ele odeia um outro simulacro: - ele odeia o Werther que ele não quer ser.

Mas a coisa é um pouco mais complicada do que isso, pois, no interior do percurso narrativo, Werther é obrigado a chocar-se diversas vezes com a "realidade", (ele se sente como uma marionete), com a dimensão de existência efetiva (Fontanille), ao modo de ser, em que, como vimos, está em disjunção com o seu novo universo de valores (ou melhor, os valores projetados em Carlota). 
Tudo se passa do seguinte modo: ao construir o simulacro dos valores que ele/quer-ser/, e projetá-lo sobre a figura de Carlota, Werther transforma Carlota numa espécie de Destinador (isto é, de doador dos valores que Werther deve desejar). É uma curiosa inversão sintáxica, também, que fica registrada nas palavras de Roland Barthes:

\section{"RAPTO. Episódio tido como inicial (mas pode ser reconstituido depois) durante o qual o sujeito apaixonado é "raptado" (captura- do e encantado) pela imagem do objeto amado..." (pág.165)}

Evidenciamos, então, que o sofrimento humano tem suas origens na confrontaçāo constante de dois eles, ambos imaginários. O que está em jogo no interior desta estrutura é a apropriação imaginária, destrutiva e infeliz de um em relação a seu outro, e como veremos mais adiante, se há libertação; como no caso Werther, é que dará o último sobressalto que vai negar o sèr, o objeto desta apropriação dominante.

Assim, Wertheréo "objeto" doquerer de Carlota (do simulacrode Carlota que Werther constrói), e esse querer é um querer do Destinador (um Dever-ser), que é, justamente, o de impor um querer ao Destinatário, transformando-o em sujeito que /quer-dever-ser/.

Diremos, pois, que Werther, apaixonado, mantém-se fiel aos valores representados por Carlota (Destinador), simulacro ao modo do parecer de uma verdadeira Carlota que não tem nada a ver com isso, que representa a encenação, os movimentos e as aparências teatrais, os efeitos mesmo de um distanciamento. Distanciamento contínuo que comporta a ameaça de onirizar toda a realidade. Há em Werther um ir e voltar de um mar de sonhos, o mundo está envolvido nestes vapores que perdem os indícios referenciais. Carlota aparece na metáfora da existência, numa cosmogonia erotizante, numa mobilidade etérea que vai torná-la o objeto, a sombra que se deixa contemplar, que vai dilacerá-lo, que o vai confrontar com seu outro. Dai o sentimento incontornável de solidão e de exilio.

\section{Fidelidade e Espera da Salvação}

Na dimensão do ser, entretanto, o sujeito Werther percebe que mesmo cumprindo fielmente o "contrato" estabelecido com o "Destinador"(Carlota, ao modo do Parecer), ele, Werther, que espera uma sanção positiva de seu fazer, recebe, apesar disso, uma sanção negativa de Carlota (que sanciona 
positivamente, em contrapartida, o fazer do anti-sujeito Alberto, "Destinatário" de um anti-destinador que são os valores representados por aquilo que Werther /quer-não-ser/).

A competência de distanciamento introduz em Werther o "ser ascético" que faz o passo anti-social da ruptura, da quebra do jogo dos espelhos, da aceitação e da encarnação dos recônditos arcanos da vida e das coisas. Certamente, a salvação não está na intersubjetividade, perdida para sempre...

Assim, por mais que Werther cumpra o "contrato" (imaginário), Carlota ("real") não poderia sancioná-lo positivamente. De repente, Werther percebe que não pode mais esperar nada de Carlota: foi abandonado. Segundo Fontanille, esse momento caracteriza a paixão do desespero, em que o sujeito, apesar de continuar fiel a seus valores, questiona a ação de seu Destinador. Normalmente, esse "abandono" levaria o sujeito a uma crise de confiança; mas com o apaixonado como Werther, isso não ocorre, ou ocorre apenas no nível cognitivo, não no passional. Werther sabe que Carlota não passará a amá-lo, qualquer que seja a sua ação. Mesmo assim, ele continua a querer ser amado. $\dot{E}$ a figura passional da obstinação: /saber-não-poder-ser/-/querer-ser/-/crerpoder-ser/ (Fontanille).

Essa obstinação do amante é assim expressa por Barthes, em Fragmentos de um discurso amoroso:

"(...) Ao mesmo tempo em que se pergunta obsessivamente porque não é amado, o sujeito apaixonado vive na crença de que na verdade o objeto amado o ama, mas não o diz (...).

"A verdade é que -paradoxo exorbitante-näo paro de acreditar que sou amado. Alucino aquilo que desejo. Cada ferida tem menos de uma dúvida que de uma traiçāo; porque só pode trair aquele que ama, só pode ter ciumes aquele que se era amado: o outro, casualmente, falha em relação ao seu ser, que é de amar, eis a origem das minhas infelicidades..." (págs. 161-162).

Constata-se um conflito interior dos actantes que faz o percurso narrativo caminhar muito devagar. As paixões, como se sabe, dizem respeito sempre a uma relação do eu e do outro. Mas o outro, neste estudo, é o interno, é o jogo 
de espelhos que não permite a tensividade recíproca ou que não chega a modificar o estado patêmico do co-actante "real". A origem da infelicidade de Werther é epistêmica, surge de um estado de crença e é o que causa sua insatisfação, ou seja, produz uma inversão: é o saber que possibilita um crer; ambos são inseparáveis. Ele sabe que Carlota é noiva, que possui uma série de valores que não são os dele, como a futilidade por exemplo e sabe que não há uma verdadeira integração passional entre os dois. Mesmo assim, ele passa a desejá-la. Então, é a partir deste saber, desta impossibilidade que. Werther irá montar, construir e gerar seu imaginário, seus símbolos, etc. que o levarão a um desdobramento internoe a estados patêmicos auto-reflexivos, como os diálogos com ele mesmo.

É essa mesma obstinação desesperada, esse círculo vicioso que põe e dispōe, que reitera duelos entre dois universos contrários, que, dialeticamente, empurra o sujeito apaixonado para um caminho sem retorno. Werther,como todo amante, está num beco sem saída: uma vez instalada a crise amorosa, ele já não pode mais voltar àquele que tinha sido; ao mesmo tempo, ele não consegue realizar-se como sujeito em conjunção com seu objeto, isto é, ele não pode concretizar a sua metamorfose (a sua transformação em outro ser).

Aos poucos, o apaixonado Werther vai-se retirando, por força desse impulso obsessivo do mundo "real" do ser para ocupar-se cada vez mais de sua enunciação solitária. Podemos verificar como, no filme, as imagens vão ficando cada vez mais impregnadas de sonho, de irrealidade - é o delírio de linguagem de Werther. A única possibilidade de existência do sujeito em crise, passa a ser esse mundo povoado de simulacros. O mundo real vira apenas um pré-texto: como diz Bạrthes,

"(...) O acontecimento, infimo, só existe através da sua repercussäo, enorme (...)"

"(...) O enamorado é um drama, se quiserimos devolver a essa palavra o sentido arcaico que Nietzsche lhe dá: 'O drama antigo tinha em vista grandes cenas declamatórias, o que excluia a açāo (esta tinha lugar antes ou atrás da cena)'. (...)" (págs. 81-82)

Como entender o suicídio de Werther? Uma revolta, uma punição dirigida ao destinador (Carlota) que não cumpriu o Contrato de confiança, abandonando-o? Uma desistência de perseguir os valores tão profundamente desejados? Mas, de qual Carlota estamos falando, se a Carlota "real" já dava mostras, pouco antes do desfecho, de dispor-se a aceitar o querer de Werther?. 
Lampejo de consciência? Teria Werther compreendido que aquela que desejava não era a Carlota real, que era "bem insípida; a personagem medíocre de uma encenação forte" (Barthes, pág. 23), mas, sim, desejava uma projeção de seu próprio amor? Se isso pode sustentar-se, entāo Werther teria compreendido que tudo o que ele desejava poderia ser destruído pela uniảo com aquela Carlota real, uma "estranha" que Werther não conhecia e não queria. A uniāo "de fato" corresponderia, portanto, a um retorno impossível a um "eu" que Werther negara.

Mas a alternativa oposta- a realização do outro "eu" de Werther, a personificação da PAIXĀO - seria uma outra impossibilidade. Diante disso, como salvar-se? Pelo suicídio, é claro.

O suicídio é a única chance que Werther tem de continuar a sua caminhada. Ele está associado, portanto, a um /Dever-ser/ indestrutível. Na visão de Barthes, o suicídio aparece como uma idéia de continuar vivo.

"As vezes, vivamente atingido por alguma circunstância fútil $e$ envolvido pela repercussão que ela provoca, me vejo de repente numäarmadilha, imobilizado numa situação (num sítio) impossivel: sỏ há duas saídas (ou...ou então...) e as duas estão igualmente trancadas: dos dois lados só tenho que me calar. Entāo a idéia de suicidio me salva, pois pode ser falada (e não me privo disso): renaş̧o e pinto essa idéia com as cores da vida, seja para dirigi-la agressivamente contra o objeto amado (chantagem bem conhecida), seja para me unir a ele fantasiosamente na morte ('descerei ao túmulo para me abraçar com você')" (pág. 185).

Werther consegue, assim, percorrer até as últimas conseqüência o caminho de seu desespero: mantém-se fiel aos valores que ama (e agride a figura que não soube representá-los) e, ao mesmo tempo, abate-se, desiste de procurálos nessa mesma figura - renuncia a uma Carlota que, ao modo do ser, é tudo aquilo quanto ele não-quer.

Suicidando-se, Werther se muda: abandona o mundo das figuras cosmológicas e vai para o único lugar de existência facultado às paixōes absolutas - o mundo interoceptivo - e se metamorfoseia em amorosidade. Vai ao reencontro do sentimento da vida, volta às forças da natureza, reinstala-se na sua mônada. 


\section{BIBLIOGRAFIA}

BARTHES, Roland. Fragmentos de um discurso amoroso. Rio, Ed. Francisco Alves, 1981.

BUARQUE DE HOLANDA, Aurélio. Novo dicionário da língua portuguesa. Rio, Ed. Nova Fronteira, s/d.

FONTANILLE, Jacques. "Le Tumulte Modale". Actes Semiotiques Bulletin. Paris, GRS-L, IX, 39, 1986.

GOETHE, Johann W. Werther. S. Paulo, Abril, 1983.

GREIMAS, A. J.e COURTÉS, J. Dicionário de semiótica. São Paulo, Ed. Cultrix, 1983.

PARRET, Herman. Le sublime du quotidien. Paris/Amsterdam/Philadelphia, Ed. Hadès-Benjamins, 1988. 